\title{
Prediction of Consumer Behavior Regarding Purchasing Remanufactured Products: A Logistics Regression Model
}

\author{
Kadri G Yilmaz', Sedat Belbag ${ }^{2}$
}

\begin{abstract}
Scarce resources, strict take-back legislations, decreasing life cycle of products and increasing competition are compelled original equipment manufacturers (OEMs) to collect and reuse their returned products. Remanufacturing is a well-known and widely used environment-friendly manufacturing to evaluate product returns. Moreover, with remanufacturing, OEMs offer environment-friendly products to environmentally concerned consumers, also known as green consumer. This study aims to develop a prediction model to determine purchase behavior of consumer for remanufactured products. We investigate the data with a survey of closed-end questions conducted among 400 residents of Ankara, Turkey. We consider several factors that influence consumers' preferences in purchasing process of remanufactured products. The suggested model predicts consumer behavior of remanufactured products with logistic regression analysis. The results show that several factors have effects on purchase behavior of consumer for remanufactured products such as low prices, company reliability and product promotion changes consumer behavior from no purchasing to purchasing remanufactured products.
\end{abstract}

Keywords: Consumer behavior, green marketing, logistics regression, remanufacturing, societal marketing. Available Online: 25-02-2016

This is an open access article under Creative Commons Attribution 4.0 License, 2016.

\section{$1.0 \quad$ INTRODUCTION}

Recently, environmental issues and waste management have increasingly become important over customer concerns. According to 2012 Commodity Flow Survey, $\$ 83,153$ million worth of waste and scraps are returned in the United States (United States Department of Transportaiton). These waste and scraps generally originate from defective or damaged products, leased product returns, and end-of-life returns

\footnotetext{
${ }^{1}$ Business Administration, Faculty of Economics and Administrative Sciences, Gazi University. Turkey. Email id: kgokhany@gmail.com

${ }^{2}$ Business Administration, Faculty of Economics and Administrative Sciences, Gazi University. Turkey. Email id: sedatbelbag@gazi.edu.tr
} 
(Jayaraman and Luo, 2007; Toffel, 2003). The decreased life cycle of products boosted the number of returned products in the last decades. Moreover, strict take-back legislations compel original equipment manufacturers (OEMs) to collect returned products from customers. Additional collection and disposal operations of returned products have led to increased transportation and disposal costs. Thus, in order to eliminate product returns and additional costs, OEMs aim to change their traditional supply chains to closed loop supply chains.

Closed loop supply chains intend to design, operate and control the supply chain system in consideration of different types and volumes of returned product over the entire life cycle of a product (Govindan et al., 2015). Moreover, closed loop supply chains involve different operations from traditional supply chains, such as repairing, remanufacturing, recycling, and disposal. Among these alternatives, remanufacturing is the most widely used form of environment-friendly manufacturing. Remanufacturing is a potential income option through regaining materials from returned products. Hence, remanufacturing is effectively implemented in many industries, such as automotive, aviation and electronics. For instance, Kodak enjoys significant cost advantages from remanufacturing of single-use cameras - up to $\$ 9$ million per year (Chengalur, 2005). Caterpillar is another example, where two different diesel engines with 20,000 parts are disassembled and rebuild, from bottom to top, per eight-hour shifts. With 14 different remanufacturing plants, Caterpillar's annual revenue reaches $\$ 1$ billion, with $20 \%$ annual growth (Jayaraman and Luo, 2007).

Despite requiring additional efforts, the remanufacturing process also provides competitive advantages over competitors. Remanufacturing offers several marketing opportunities to companies such as reaching green consumers and entering new environmental concerning markets. Increased environmental consciousness of consumers reshapes their consumption patterns (Shrum et al., 1995), which - all together -contributes to popularization of concepts, such as remanufactured products and green marketing, as well as promoting conscious utilization of resources (natural resources, energy, etc.) (Atasu et al., 2008; Geyer et al., 2007; Giutini and Gaudette, 2003). Green marketing is a concept based on environmental consciousness and analyzed in many studies (Oyewole, 2001; Chamorro et al., 2009; Prothero, 1990; Ginsberg and Bloom, 2004; Peattie, 2001; Polonsky, 1994; Peattie and Charter, 2003; Polonsky and Rosenberger, 2001; Roberts, 1996; Prakash, 2002; Ottman et al. 2006; Rex and Baumann, 2007; Liu et al., 2012; Dief and Font, 2010; Iraldo et al., 2013; Biswas and Roy, 2015).

The evolution of marketing and the modeling of green marketing is parallel by process. Evolving through the concepts of production, product, sales, modern marketing and societal marketing (Kotler and Amstrong, 2008; Kotler and Keller 2012; Hutton, 1996), marketing has reached its final phase where the focus is on the society and social welfare as well as the consumer. Nowadays, social responsibility awareness is a strong aspect for businesses to improve their image in the eyes of the consumers. Thus, companies adopt a marketing approach beyond customer-oriented approach where the focus is on every segment of the society. The attached importance to the benefit of the society as a whole as well as the efforts for efficient use of limited resources are important topics shaping marketing strategies of contemporary businesses (Peattie and Peattie, 2009; Gaski, 1985; Prothero, 1990; Carrigan, 1995; Dos Santos, 2009; King et al., 2000).

Figure 1: Societal marketing concept

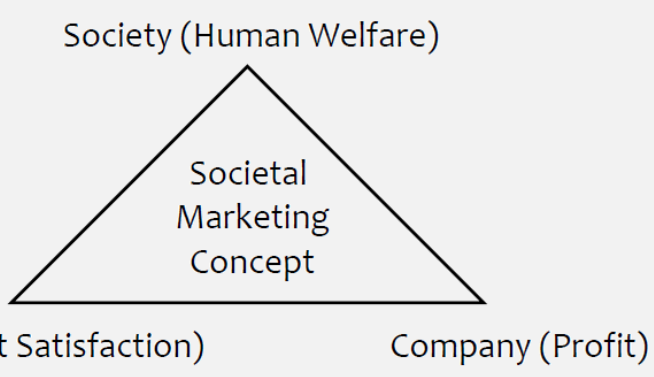

Consumer (Want Satisfaction)

Source: (Kotler and Amstrong, 2008) 
The social interest in green marketing encourage companies to produce environmental-friendly products such as remanufactured products. Remanufactured products have same functions as new traditional products and positive effects on the environment. These products provide both a private benefit to customer and a public benefit to society. On the other hand, the evaluation of consumer behavior about remanufactured products forms several questions for companies to answer in marketing process. For example, what are the key factors that affect consumer behavior or how can consumer behavior be predicted with regard to remanufactured products?

The contribution of this paper is to predict consumer behavior regarding purchasing remanufactured products. We reveal and underline several factors that affect the prediction process of consumer behavior for remanufactured products. We use logistics regression method to predict consumer behavior according to the related factors for remanufactured products. The results show that the suggested model predicts consumer behavior with considering several important factors such as low price, information on previous condition and promotion.

The remainder of the paper is organized as follows. Section 2 outline the review of the relevant literature. Section 3 provides the research method and the scope of the study. Section 4 presents the results of the logistics regression model. Lastly, Section 5 concludes the study with presenting a discussion of the study as well as suggestions for future studies.

\subsection{LITERATURE REVIEW}

Environmentally concerned customers have led to an expanding market that emerged with respect to environment-friendly (green) products. Recycled products, organic products, energy-saved electronics and remanufactured products are some major examples of environment-friendly products. Remanufacturing aims to produce environment-friendly products, however, consumers' perception of remanufactured products is a rarely studied topic in literature. Early studies intend to shed light on consumer perception of recycling as well as recycled products. Mobley et al. (1995) examine consumer approach to recycled products as well as effective factors in the evaluation process of consumers. Their study suggests that, in consumers' opinion recycled products are not evaluated as new products. However, in consumer evaluation process a respected brand may have a positive influence over recycled products. Biswas et al. (2000) analyze the relation between past recycling behavior and consumer attitude toward recycled products. Accordingly, companies should develop recycled product related messages to affect social marketers as well as promoting consumption of recycled products. Several studies focus on topics related with used products in marketing area. Some examples are the connection between used and new product markets (Thomas, 2003), consumer behavior in used products trade (Hickey and Fitzpatrick, 2008), the pricing issue of used products (Brough and Isaac, 2012).

More recent studies aim to illustrate the importance of consumer perception of remanufactured products. Michaud and Llerena (2011) investigate consumers' willingness to pay (WTP) for remanufactured products by using experimental auctions. They concluded that a large number of consumers assume remanufactured products to have a lower quality level than that of new products. However, OEMs can reverse this perception by offering quality assurance. Price and quality are considered as key factors to affect purchase decision, especially among environmental conscious consumers. According to Atasu et al. (2008), a large number of consumers usually approach remanufactured products as low-price alternatives to new products. Subramanian and Subramanyam (2012) focus on explanatory factors of the purchase price differences between new and remanufactured products. They conclude that reputation and identity of seller as well as their warranty strength have positive influence on remanufactured products. Hazen et al. (2012) investigate the significance of ambiguity tolerance, perceived quality, and willingness to pay, regarding remanufactured products. The results illustrate that ambiguity has an adverse effect on consumers' perception of quality as well as their willingness to pay for remanufactured products. Hamzaoui Essoussi and Linton (2010), point out the impact of perceived functional risk related to consumer purchase decisions. As the uncertainty increase 
the perceived functional risk, the remanufactured product will become economically less attractive to customers. Jiménez -Parra et al. (2014) stated the key factors behind the potential consumer behavior as social circles, price and remanufacturer's reputation.

In summary, although some studies present several factors that have a potential to affect consumer behavior for remanufactured products, none of them investigate the prediction of purchase behavior of consumer for remanufactured products in the literature. On the other hand, this study aims to design a model that predicts purchase behavior of consumer for remanufactured products with respect to factors that influence consumers' preferences to purchase remanufactured products.

\subsection{RESEARCH METHOD}

We collect the data utilized in this study, with a survey of closed-end questions conducted among residents of Ankara province. The questionnaire is designed to project purchase behavior of consumer for remanufactured products. We carried out the questionnaire among 400 participants, and random sampling is used. In the questionnaire statements are presented with five point Likert scale (1: Strongly Disagree, 2: Disagree, 3: Neutral, 4: Agree, 5: Strongly Agree). Prior to the survey, we conduct a preliminary survey among 100 participants selected with random sampling. The reliability analysis carries out after the preliminary survey pointed to Cronbach Alfa value to be $84.1 \%$ (Table 1). Besides, a correlation analysis check any possible correlation between the independent variables used in the analysis. Thus, the result of the correlation analysis retrieve no meaningful relation between the independent variables (Table 1). The variables listed in Table 2 are: Low prices (LOWP), warranty disclaimer (WDIS), brand image (BRIM), perceived quality (PERQ), the product being used (UPRO), information on previous condition (PCON), performance expectations (PEXP), product type (TYPE), remanufactured product making less harm to the environment (LEHA), company reliability (CREL), societal perspective on the product (SPER), product promotion (PROM) and background of problems with the product (BPRO).

\begin{tabular}{|rrrr}
\hline \multicolumn{3}{c}{ Table 1: Reliability statistics } \\
\hline Cronbach's Alpha & $\begin{array}{r}\text { Cronbach's Alpha Based on } \\
\text { Standardized Items }\end{array}$ & $\begin{array}{r}\text { Number of } \\
\text { Items }\end{array}$ \\
.841 & .843 & 13 \\
\hline
\end{tabular}

We develop our hypotheses with regard to factors that affect the prediction of consumer behavior for remanufactured products. The hypotheses mostly depend on predict value of the factors. Acceptance and rejection of any hypothesis belongs to significance value of the factor in the result of logistics regression.

H1: Low price affects the prediction consumer behavior when purchasing remanufactured products. H2: Warranty disclaimer affects the prediction consumer behavior when purchasing remanufactured products.

H3: Brand image affects the prediction consumer behavior when purchasing remanufactured products.

$\mathrm{H} 4$ : Perceived quality affects the prediction consumer behavior when purchasing remanufactured products.

$\mathrm{H}_{5}$ : The product being used affects the prediction consumer behavior when purchasing remanufactured products.

H6: Information on previous condition affects the prediction consumer behavior when purchasing remanufactured products.

H7: Performance expectations affects the prediction consumer behavior when purchasing remanufactured products.

H8: Product type affects the prediction consumer behavior when purchasing remanufactured products. H9: Remanufactured product making less harm to the environment affects the prediction consumer behavior when purchasing remanufactured products. 
H10: Company reliability affects the prediction consumer behavior when purchasing remanufactured products.

H11: Societal perspective on the product affects the prediction consumer behavior when purchasing remanufactured products.

H12: Product promotion affects the prediction consumer behavior when purchasing remanufactured products.

H13: Background of problems with the product affects the prediction consumer behavior when purchasing remanufactured products.

\begin{tabular}{|c|c|c|c|c|c|c|c|c|c|c|c|c|c|}
\hline & LOWP & WDIS & BRIM & PERQ & UPRO & PCON & PEXP & TYPE & LEHA & CREL & SPER & PROM & BPRO \\
\hline LOWP & 1.000 & & & & & & & & & & & & \\
\hline WDIS & .606 & 1.000 & & & & & & & & & & & \\
\hline BRIM & .499 & .539 & 1.000 & & & & & & & & & & \\
\hline PERQ & .605 & .561 & .527 & 1.000 & & & & & & & & & \\
\hline UPRO & -.063 & .073 & .005 & .202 & 1.000 & & & & & & & & \\
\hline PCON & .166 & .250 & .198 & .420 & .263 & 1.000 & & & & & & & \\
\hline PEXP & .365 & .319 & .298 & .480 & .077 & .599 & 1.000 & & & & & & \\
\hline TYPE & .273 & .421 & .296 & .471 & .073 & .371 & .413 & 1.000 & & & & & \\
\hline LEHA & .353 & .301 & .189 & .433 & .215 & .124 & .296 & .320 & 1.000 & & & & \\
\hline CREL & .342 & .423 & .376 & .501 & .079 & .352 & .425 & .555 & .482 & 1.000 & & & \\
\hline SPER & .129 & .057 & .210 & 197 & .064 & .063 & .230 & .140 & .318 & .265 & 1.000 & & \\
\hline PROM & .485 & .416 & .239 & .445 & -.006 & .262 & .228 & .308 & .360 & .446 & .239 & 1.000 & \\
\hline BPRO & .059 & .125 & .031 & .127 & .118 & .352 & .467 & .225 & .190 & .374 & .178 & .340 & 1.000 \\
\hline
\end{tabular}

Logistic regression is a multivariate regression and permits an analysis where several independent variables forecast a dependent variable in the presence or absence of an outcome based on the values of a set of predictor variables. The main advantage of logistic regression is the usability with each type of variable. For example, variables may be either continuous or discrete, or any combination of both types and there is no need a necessity to have normal distributions (Lee, 2005). By nature, logistics regression analysis is not affected by dependent and independent variables being qualitative, quantitative or categorical. Therefore, logistics regression is beneficial to the researches for the interpretation of binary and categorical data, especially (Agresti, 1996).

In this study, we utilize a logistics regression method to predict purchase behavior of consumer for remanufactured products. Because, the dependent and independent variables are qualitative, we use logistics regression analysis. Moreover, logistics regression analysis identifies the relation between purchase behavior of consumer for remanufactured products and the factors that influence consumers' preferences to purchase these remanufactured products. The dependent variable is analyzed with respect to the 13 independent variables presented in Table 2. The logistics regression analysis assigns the value "o" to the "yes" answers provided to the independent variable "Would you buy a remanufactured product?" and the value " 1 " to the "no" answers. Hence, the results are interpreted with respect to these values in the following section.

\subsection{RESULTS AND DISCUSSION}

The model analyzed in this study is a logistics regression model that is designed to predict whether consumers purchase the remanufactured products with respect to the factors influencing the process. Hence, the model is acceptable as the overall significance level of this model is below 0.05 . As shown in Table 3, chi-square value for the model is 77.889. Besides, the significance level determined from Hosmer and Lemeshow Tests - which shows the goodness of fit - being close to 1 supports the feasibility of the model (Table 4). 


\begin{tabular}{|c|c|c|c|c|}
\hline \multicolumn{5}{|c|}{ Table 3: Omnibus Tests of Model Coefficients } \\
\hline & & i-square & $\mathrm{df}$ & Sig \\
\hline \multirow[t]{3}{*}{ Step 1} & Step & 77.889 & 13 & .000 \\
\hline & Block & 77.889 & 13 & .000 \\
\hline & Model & 77.889 & 13 & .000 \\
\hline
\end{tabular}

\begin{tabular}{rrrr}
\hline \multicolumn{5}{c}{ Table 4: Hosmer and Lemeshow Test } \\
\hline Step & Chi-square & df & Sig. \\
\hline 1 & 6.038 & 8 & .643 \\
\hline
\end{tabular}

Table 5 demonstrates the predictions of the model with respect to logistics regression analysis. Accordingly, the average prediction of the proposed model is $70 \%$. In other words, the proposed model can make $70 \%$ correct predictions of consumer purchase decision of remanufactured products.

\begin{tabular}{|c|c|c|c|c|c|}
\hline \multicolumn{6}{|c|}{ Table 5: Classification table } \\
\hline & \multirow{3}{*}{\multicolumn{2}{|c|}{ Observed }} & & & Predicted \\
\hline & & & \multicolumn{2}{|c|}{ Depended Variable } & \multirow{2}{*}{$\begin{array}{r}\text { Percentage } \\
\text { Correct }\end{array}$} \\
\hline & & & Yes & No & \\
\hline \multirow[t]{3}{*}{ Step 1} & Depended & Yes & 206 & 32 & 86.6 \\
\hline & Variable & No & 89 & 73 & 46.1 \\
\hline & \multicolumn{3}{|c|}{ Overall Percentage } & & 70.0 \\
\hline
\end{tabular}

Table 6 depicts that, with respect to consumer preferences of remanufactured products, all independent variables reckoned in the model have no effect on the dependent variable, whatsoever. In prediction of the dependent variable, six independent variables have a significance level below 0,05\%: low prices (LOWP), the product being used (UPRO), information on previous condition (PCON), company reliability (CREL), product promotion (PROM), background of problems with the product (BPRO). Thus, it is not possible to use the remaining independent variables above 10\% significance level. According to logistics regression results, six hypotheses are accepted $\left(\mathrm{H}_{1}, \mathrm{H}_{5}, \mathrm{H} 6, \mathrm{H}_{10}, \mathrm{H}_{12}, \mathrm{H}_{13}\right)$ in consideration of their significance levels. We reject the remained seven hypotheses $\left(\mathrm{H}_{2}, \mathrm{H}_{3}, \mathrm{H} 4, \mathrm{H} 7, \mathrm{H} 8, \mathrm{H} 9, \mathrm{H} 11\right)$ in consideration of their significance levels.

\begin{tabular}{lrrrrrr}
\hline \multicolumn{7}{c}{ Table 6: Variables in the equation } \\
\hline Variables & $\beta$ & S.E. & Wald & df & Sig. & Exp(B) \\
\hline LOWP & -.382 & .131 & 8.507 & 1 & .004 & .682 \\
WDIS &. .237 & .159 & 2.225 & 1 & .136 & .789 \\
BRIM & .013 & .143 & .008 & 1 & .927 & 1.013 \\
PERQ & -.161 & .152 & 1.116 & 1 & .291 & .852 \\
UPRO & .278 & .126 & 4.861 & 1 & .027 & 1.321 \\
PCON & .315 & .158 & 3.969 & 1 & .046 & 1.370 \\
PEXP & .027 & .167 & .026 & 1 & .873 & 1.027 \\
TYPE & .017 & .132 & .017 & 1 & .896 & 1.017 \\
LEHA & -.069 & .114 & .366 & 1 & .545 & .933 \\
CREL & -.328 & .166 & 3.906 & 1 & .048 & .720 \\
SPER & .060 & .108 & .310 & 1 & .577 & 1.062 \\
PROM & -.336 & .126 & 7.168 & 1 & .007 & .714 \\
BPRO & .317 & .144 & 4.835 & 1 & .028 & 1.373 \\
Constant & 1.161 & .798 & 2.120 & 1 & .145 & 3.194 \\
\hline
\end{tabular}

Moreover, their Wald value being above 2, all independent variables used in prediction of the dependent variable are determined to have an influence on the model. The value of $\beta$ informs decision maker about the influence direction of the factor. So, with respect to the $\beta$ value of the low price (LOWP), one may interpret that consumer's purchase decision regarding a remanufactured product may differ in each purchase. In this model, the product being used (UPRO) has a negative influence on the consumer purchase decision regarding a manufactured product. Likewise, information on previous condition (PCON) changes consumer purchase decision from yes to no. Company reliability (CREL) as well as 
product promotion (PROM) changes consumer behavior from no purchase to purchase. Finally, background of problems with the product (BPRO) changes consumer behavior from purchase to no purchase.

The result of logistics regression reveal that the dependent variable of the model is predictable with respect to six independent variables. Accordingly, we reconstruct the proposed model with respect to these six independent variables and reanalyze it by using the logistics regression method. Similar to the previous analysis, the significance level of the model using only six independent variables is determined to be below $0.05 \%$ (Table 7). Thus, the value inferred in Hosmer and Lemeshow Test is $0.754-$ which is closer to 1 than the previous value (Table 8).

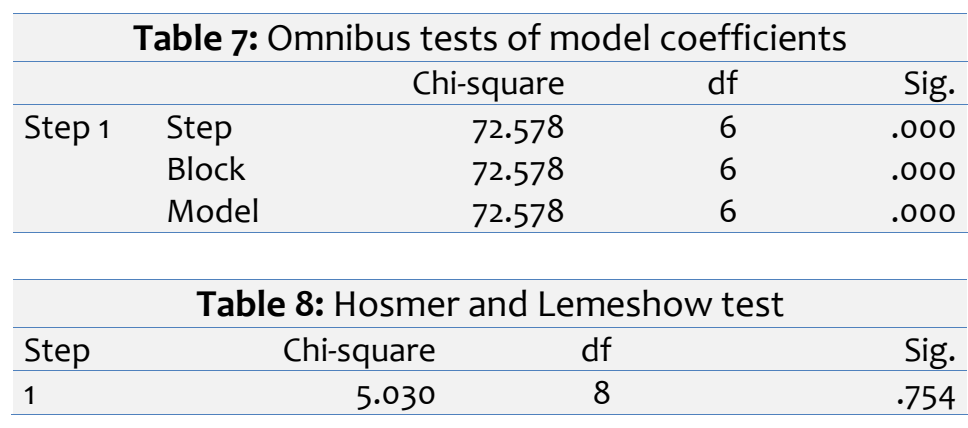

According to Table 9, all independent variables used in the new regression analysis meet the $0.05 \%$ significance level requirement. Similarly, compared to the previous one, there is a noteworthy increase in Wald values of all independent variables. The $\beta$ values of independent variables also signify a certain increase than that of the previous analysis. In fact, such an increase points out independent variables being more influential on the prediction of the dependent variable. Consequently, the logistics regression analysis reveals several important results for consumer behavior regarding purchasing remanufactured products. First, merely six of the initially identified 13 independent variables are able to render $0.05 \%$ significance level. Second, low prices (LOWP), company reliability (CREL), and product promotion (PROM) changes consumer behavior from previous no purchase decision to purchase. Finally, the product being used (UPRO), information on previous condition (PCON), and background of problems with the remanufactured product (BPRO) have a negative effect over consumer behavior from purchase to no purchase decision.

\begin{tabular}{lcccrrr}
\hline \multicolumn{7}{c}{ Table 9: Variables in the Equation } \\
\hline Variables & $\mathrm{B}$ & S.E. & Wald & df & Sig. & Exp(B) \\
\hline LOWP & -.503 & .116 & 18.907 & 1 & .000 & .605 \\
UPRO & .250 & .122 & 4.199 & 1 & .040 & 1.285 \\
PCON & .269 & .148 & 3.285 & 1 & .070 & 1.308 \\
CREL & -.426 & .147 & 8.427 & 1 & .004 & .653 \\
PROM & -.340 & .120 & 8.012 & 1 & .005 & .712 \\
BPRO & .310 & .140 & 4.899 & 1 & .027 & 1.364 \\
Constant & .957 & .727 & 1.729 & 1 & .189 & 2.603
\end{tabular}

\subsection{CONCLUSION}

In recent years, many companies (especially OEMs) are compelled to collect return products as to strict take-back laws, scarce resources, and environmentally concerned consumers. Remanufacturing is a widely used method in eliminating waste and scraps as well as utilizing returned products, while triggering new marketing opportunities. Thus, purchase behavior of consumer for remanufactured products is a rarely studied topic in the marketing literature.

This study focuses on proposing a new model to project consumers' purchase decision for remanufactured products. We design a questionnaire to identify the factors acting upon purchase decisions of consumers' - both yes and no - regarding such products; hence, logistics regression model 
is used in their analysis. In proposed model, the dependent variable is consumers' decision, while the independent variables are the effective factors over consumer behavior. The analysis reveals that low prices, warranty disclaimer, the product being used, information on previous condition, company reliability, product promotion and background of problems with the product are the main and the most influential factors in consumers' decision process of remanufactured products. On one hand, low prices, warranty disclaimer, company reliability and product promotion are the factors to induce purchasing remanufactured products. On the other hand, the product being used, information on previous condition, background of problems with the remanufactured product stand as the factors leading to no purchase of such products.

It is always possible to repeat this study through classifying the remanufactured products by sector. Consumers' expectation on product lines as well as their benefits may differ from group to group. Likewise, consumers' perception of remanufactured products may also vary for separate product lines. Thus, distinction by sector or by product may reveal different results in further studies. Moreover, personal traits of consumers (i.e., demographic, psychographic, behavioral) have a potential to influence purchasing decision. Therefore, focusing on such personal traits in further studies may entail progressive results, as well.

\section{REFERENCES}

Agresti, A. (1996). An introduction to categorical data analysis (Vol. 135). New York: Wiley.

Atasu, A., Sarvary, M., \& Van Wassenhove, L. N. (2008). Remanufacturing as a marketing strategy. Management Science, 54(10), 1731-1746.

Biswas, A., Licata, J. W., McKee, D., Pullig, C., \& Daughtridge, C. (2000). The recycling cycle: An empirical examination of consumer waste recycling and recycling shopping behaviors. Journal of Public Policy \& Marketing, 19(1), 93-105.

Biswas, A., \& Roy, M. (2015). Green products: an exploratory study on the consumer behaviour in emerging economies of the East. Journal of Cleaner Production,87, 463-468.

Brough, A.R., Isaac, M.S. (2012). Finding a home for products we love. How buyer usage intent affects the pricing of used goods. Journal of Marketing, 76(4), 78-91.

Carrigan, M. (1995). POSIT-ive and negative aspects of the societal marketing concept: Stakeholder conflicts for the tobacco industry. Journal of Marketing Management, 11(5), 469-485.

Chamorro, A., Rubio, S., \& Miranda, F. J. (2009). Characteristics of research on green marketing. Business Strategy and the Environment, 18(4), 223-239.

Chengalur, S. (2005). Retrieved 09 24, 2013, from United States Environmental Protection Agency: http://www.epa.gov/climateleadership/documents/events/may2005/chengaluro505.pdf.

Dief, M. E., \& Font, X. (2010). The determinants of hotels' marketing managers' green marketing behaviour. Journal of Sustainable Tourism, 18(2), 157-174.

Dos Santos, M. A. O. (2009). Achieving sustainable competitive advantage through the implementation of the societal marketing concept by a major retailer in South Africa. Journal of Global Business and Technology, 5(2), 39.

Gaski, J. F. (1985). Dangerous territory: The societal marketing concept revisited. Business Horizons, 28(4), 42-47.

Geyer, R., Van Wassenhove, L. N., \& Atasu, A. (2007). The economics of remanufacturing under limited component durability and finite product life cycles. Management Science, 53(1), 88-100.

Ginsberg, J. M., \& Bloom, P. N. (2004). Choosing the right green-marketing strategy. MIT Sloan Management Review, 46(1), 79.

Giutini, R., \& Gaudette, K. (2003). Remanufacturing: The next great opportunity for boosting US productivity. Business Horizons, 46(6), 41-48.

Govindan, K., Soleimani, H., \& Kannan, D. (2015). Reverse logistics and closed-loop supply chain: A comprehensive review to explore the future. European Journal of Operational Research, 240(3), 603626. 
Hamzaoui Essoussi, L., \& Linton, J. D. (2010). New or recycled products: how much are consumers willing to pay?. Journal of Consumer Marketing, 27(5), 458-468.

Hazen, B. T., Overstreet, R. E., Jones-Farmer, L. A., \& Field, H. S. (2012). The role of ambiguity tolerance in consumer perception of remanufactured products. International Journal of Production Economics, 135(2), 781-790.

Hickey, S.W., Fitzpatrick, C., (2008). Combating adverse selection in secondary PC markets. Environment Science \& Technology, 42(8), 3047-3052.

Hutton, J. G. (1996). Integrated marketing communications and the evolution of marketing thought. Journal of Business Research, 37(3), 155-162.

Iraldo, Frey, M.,Testa, F., \& Bartolozzi, I. (2013). An application of Life Cycle Assessment (LCA) as a green marketing tool for agricultural products: the case of extra-virgin olive oil in Val di Cornia, Italy. Journal of Environmental Planning and Management, 57(1), 78-103.

Jayaraman, V., \& Luo, Y. (2007). Creating competitive advantages through new value creation: a reverse logistics perspective. The Academy of Management Perspectives, 21(2), 56-73.

Jiménez-Parra, B., Rubio, S., \& Vicente-Molina, M. A. (2014). Key drivers in the behavior of potential consumers of remanufactured products: a study on laptops in Spain. Journal of Cleaner Production, 85, 488-496.

King, B., McVey, M., \& Simmons, D. (2000). A societal marketing approach to national tourism planning: Evidence from the South Pacific. Tourism Management, 21(4), 407-416.

Kotler, P., \& Armstrong, G. (2008). Principles of Marketing. Twelfth Edition, Pearson Education.

Kotler, P., \& Keller, K. L. (2012). Marketing Management. Fourteenth Edition, Upper Saddle River, N.J: Prentice Hall.

Lee, S. (2005). Application of logistic regression model and its validation for landslide susceptibility mapping using GIS and remote sensing data. International Journal of Remote Sensing, 26(7), 14771491.

Liu, S., Kasturiratne, D., \& Moizer, J. (2012). A hub-and-spoke model for multi-dimensional integration of green marketing and sustainable supply chain management. Industrial Marketing Management, 41(4), 581-588.

Michaud, C., \& Llerena, D. (2011). Green consumer behaviour: an experimental analysis of willingness to pay for remanufactured products. Business Strategy and the Environment, 20(6), 408-420.

Mobley, A. S., Painter, T. S., Untch, E. M., \& Rao Unnava, H. (1995). Consumer evaluation of recycled products. Psychology \& Marketing, 12(3), 165-176.

Ottman, J. A. , Stafford, E. R., \& Hartman, C. L. (2006). Avoiding Green Marketing Myopia: Ways to Improve Consumer Appeal for Environmentally Preferable Products., Environment: Science and Policy for Sustainable Development, 48(5), 23-36

Oyewole, P. (2001). Social costs of environmental justice associated with the practice of green marketing. Journal of Business Ethics, 29(3), 239-251.

Peattie, K. (2001). Towards Sustainability: The Third Age of Green Marketing. The Marketing Review, 2(2), 129-146.

Peattie, K., \& Charter, M. (2003). Green marketing. The marketing book, Butterworth-Heinemann, 5, 726755.

Peattie, K., \& Peattie, S. (2009). Social marketing: A pathway to consumption reduction?. Journal of Business Research, 62(2), 260-268.

Polonsky, M. J. (1994). An introduction to green marketing. Electronic Green Journal, 1(2), 1-10

Polonsky, M. J., \& Rosenberger, P. J. (2001). Reevaluating green marketing: a strategic approach. Business Horizons, 44(5), 21-30.

Prakash, A. (2002). Green marketing, public policy and managerial strategies. Business Strategy and the Environment, 11(5), 285-297.

Prothero, A. (1990). Green consumerism and the societal marketing concept: marketing strategies for the 1990's. Journal of Marketing Management, 6(2), 87-103.

Rex, E., \& Baumann, H. (2007). Beyond ecolabels: what green marketing can learn from conventional marketing, Journal of Cleaner Production, 15, 567-576

Roberts, J. A. (1996). Green consumers in the 1990s: profile and implications for advertising. Journal of Business Research, 36(3), 217-231. 
Shrum, L. J., McCarty, J. A., \& Lowrey, T. M. (1995). Buyer characteristics of the green consumer and their implications for advertising strategy. Journal of Advertising, 24(2), 71-82.

Subramanian, R., \& Subramanyam, R. (2012). Key factors in the market for remanufactured products. Manufacturing \& Service Operations Management, 14(2), 315-326.

Thomas, V.M., (2003). Demand and dematerialization impacts of second-hand markets. Reuse of more use? Journal of Industrial Ecology, 7(2), 65-78.

Toffel, M. W. (2003). The growing strategic importance of end-of-life product management. California Management Review, 45(3), 102-129.

United States Department of Transportaiton. (n.d.). Retrieved 09 20, 2014, from http://www.rita.dot.gov/bts/sites/rita.dot.gov.bts/files/publications/commodity_flow_survey/2012/ united_states/table6.html. 